\title{
Short communication: Effect of age at group housing on behavior, cortisol, health, and leukocyte differential counts of neonatal bull dairy calves ${ }^{1}$
}

\author{
E. M. Abdelfattah, ${ }^{*}$ M. M. Karousa, ${ }^{*}$ D. C. Lay Jr., $\dagger$ J. N. Marchant-Forde, $\dagger$ and S. D. Eicher† ${ }^{2}$ \\ *Department of Animal Hygiene, Behavior and Management, Faculty of Veterinary Medicine, Benha University, Qalyubia, Moshtohor 13736, Egypt \\ †USDA-Agricultural Research Service, Livestock Behavior Research Unit, West Lafayette, IN 47907
}

\begin{abstract}
To determine the effect of age at grouping on behavior, health, and production of dairy bull calves, 90 Holstein-Friesian bull calves were housed in individual pens until moved to 1 of 3 treatments. Calves were housed in groups of 3 calves at $3 \mathrm{~d}$ old (GH3), $7 \mathrm{~d}$ old (GH7), or $14 \mathrm{~d}$ old (GH14) until 7 wk of age. Ten groups of 3 calves for each treatment were used, with 5 pens/ treatment in each of 2 replications (10 pens/treatment, 3 treatments, 3 calves/treatment; 90 calves total). Direct behavioral observations using instantaneous scan sampling every $10 \mathrm{~min}$ were conducted twice per week for $7 \mathrm{wk}$. At the same times, video data were recorded for continuous observations at feeding time to observe the overall activity of group-housed calves. Hip height, heart girth, and health scores were recorded weekly and body weight was recorded at the start and end of the study. Calves in GH3 spent more time playing and but more time cross-sucking and displacing other calves from milk bottles. Calves engaged in social interaction as early as $3 \mathrm{~d}$ of age, and social interactions between 3 to 6 wk of age increased markedly. Calves housed in GH14 vocalized more than did calves in GH7 and GH3. No difference was found between treatments in growth performance. Calf fecal, cough, and nasal and ocular discharge scores, differential leukocyte counts, and plasma cortisol concentrations were not affected by age at grouping. However, during the first week of grouping, when calves were moved from individual pens to group pens, some calves were unable to find their milk bottles and required guidance. In conclusion, these data show no adverse effects on health or performance and some benefits on social behavior for early (d 3) grouping of calves.
\end{abstract}

\footnotetext{
Received January 23, 2017.

Accepted August 25, 2017.

${ }^{1}$ Mention of trade names or commercial products in this paper is solely for the purpose of providing specific information and does not imply recommendation or endorsement by the US Department of Agriculture.

${ }^{2}$ Corresponding author: Susan.Eicher@ars.usda.gov
}

Key words: behavior, group housing, neonate, wellbeing

\section{Short Communication}

Isolation of calves from their dams and peers through individual housing may compromise the welfare of the calf (Costa et al., 2015; Meagher et al., 2015; Valníčková et al., 2015) due to lack of social contact. Seven out of 10 calves (USDA, 2011) are housed in individual housing until after several early stressors that influence optimum health occur, such as early transportation and enteric disease vulnerability in the first week of life (Hulbert and Moisá, 2016). Earlier group housing has been beneficial for calves and is necessary in some calf systems such as in automated feeding systems (Costa et al., 2016). Pair housing of dairy calves reduced behavioral responses to weaning and human handling and improved performance when calves were mixed with a larger group after weaning (De Paula Vieira et al., 2010). Housing young dairy calves in groups of 3 increased social interactions, calf starter intake, and ADG compared with individual housing of calves (Cobb et al., 2014), and pair housing and enhanced milk allowance increased performance and play behavior in dairy calves (Jensen et al., 2015). However, some obstacles still exist; Jensen (2007) reported that dairy calves introduced individually to a large dynamic group of 16 to 24 calves at $6 \mathrm{~d}$ of age faced more competition for access to a computer-controlled milk feeder and required more guidance than calves introduced at $14 \mathrm{~d}$ of age. Jensen and Larsen (2014) discovered benefits of pair housing calves in social tests and noted that physical contact with another calf altered responses to a novel environment. Although Meagher et al. (2015) showed that early pairing ( $6 \mathrm{~d}$ ) enhanced learning, no studies in production settings have adequately addressed the exact age within the $3 \mathrm{wk}$ of life is most appropriate for grouping to maintain calf health and allow social behavior. Therefore, the objective of the current study was to determine the effects of age at grouping - 3,7 , or $14 \mathrm{~d}$ - on behavior, health, and growth of Holstein bull calves. 
Experimental procedures were approved by the Purdue Animal Care and Use Committee (PACUC, Protocol No. 1112000434). Ninety Holstein bull calves (12 to $36 \mathrm{~h}$ after birth) were provided by and reared at a commercial dairy calf farm in Indiana. The experiment was conducted in 2 replicates: spring (from March to May) and fall (September to November). Upon arrival, calves were housed in pens with visual but not tactile contact with other calves. Individual pens consisted of a polyethylene hutch $(220 \times 122 \times 140 \mathrm{~cm})$ and an outside run $(147 \times 109 \times 117 \mathrm{~cm})$ constructed of wire fence. Group runs were $147 \times 357 \times 117 \mathrm{~cm}$. All management procedures were in accordance with the standard operating procedures of the farm.

Calves from individual pens were handled to measure initial BW, and blood was collected into EDTA tubes to check for total plasma protein concentration. The mean initial $\mathrm{BW} \pm \mathrm{SEM}$ was $43.14 \pm 0.55 \mathrm{~kg}$. Only calves with plasma protein concentrations greater than $5 \mathrm{~g} /$ $\mathrm{dL}$ at 24 to $48 \mathrm{~h}$ of age were used in the experiment (2 were excluded from the experiment due to low plasma protein concentrations). Calves were assigned randomly to 1 of 3 treatments (balanced according to BW, hip height, and heart girth upon entry). Treatments were as follows: (1) calves were individually housed until $3 \mathrm{~d}$ $\pm 1 \mathrm{~d}$ old and then grouped until the end of the experiment (GH3; $\mathrm{n}=10$ pens); (2) calves were individually housed until $7 \mathrm{~d} \pm 1 \mathrm{~d}$ old and then grouped until the end of the experiment (GH7; $\mathrm{n}=10$ pens); and (3) calves were individually housed until $14 \mathrm{~d} \pm 1 \mathrm{~d}$ old and then grouped until the end of the experiment (GH14; n $=10$ pens). The group hutches were formed by combining 3 run areas together by removing the fence in front of 3 individual hutches and surrounding them with one fence, so that each group of hutches included 3 calves, 3 hutches, and 1 run. At grouping, milk bottles were placed in the same location as they were on individual pens, directly in front of each hutch at the same height. Five pens of each treatment were formed within each of 2 experimental replications. For the whole experiment, there were 3 calves per each of 10 pens and 3 ages at grouping, equaling 90 calves. Calves were fed $6 \mathrm{~L}$ of pooled colostrum within $8 \mathrm{~h}$ of birth and $3.8 \mathrm{~L} / \mathrm{d}$ of pasteurized waste milk by bottle at 0600 and $1430 \mathrm{~h}$ from birth to $14 \mathrm{~d}$ of age. From d 15 to 49, calves were fed 5.7 $\mathrm{L}$ of milk replacer per day. Milk replacer was $24 \% \mathrm{CP}$ and $28 \%$ crude fat (CalfLand, Watertown, WI). From d 50 to 57 , milk replacer was reduced to $1.9 \mathrm{~L} / \mathrm{d}$ until complete weaning at d $57 \pm 2$. Calves were assisted with milk consumption when necessary and protected from other calves consuming their milk by guiding the encroaching calf back to their nipple. Calves had ad libitum access to a starter mixture, and fresh water in buckets outside of the hutch during the entire experi- ment. Starter consisted of $18.8 \%$ CP, $4.1 \%$ fat, $7.2 \%$ crude fat, $1.1 \% \mathrm{Ca}, 00.46 \% \mathrm{P}, 1.2 \% \mathrm{NaCl}, 0.4 \% \mathrm{Na}, 0.3$ $\mathrm{mg} / \mathrm{kg} \mathrm{Se}$, and 14,639 IU $/ \mathrm{kg}$ of vitamin A. Monensin was added at $39.7 \mathrm{~g} /$ ton (short ton). After grouping, all calves were observed for any refusal of milk or excessive cross-sucking; no refusals were observed. All calves were vaccinated with Calfguard at birth (Pfizer Animal Health, NY) and Draxxin (Zoetis, Florham Park, NJ) at 1 and $28 \mathrm{~d}$ of age. Calves remained on the study 2 wk after weaning.

Recording of behaviors (Table 1) started at d 3 and was conducted twice a week for 7 wk. Two methods were used to record the behavior of calves (Martin and Bateson, 2007). The first method was an instantaneous scan, sampling every $10 \mathrm{~min}$ for $3 \mathrm{~h}$, registered from 1100 to $1400 \mathrm{~h}$ and focused on location of calves (in, out, or transition to hutch), posture (standing or lying), and activities [vocalizing, eating, drinking, moving, and oral manipulation of pen, or licking other calves (social grooming), elimination, rumination, cross-sucking, and play behaviors (locomotive, social, and object play were combined into a single play category due to low occurrence)]. Two trained observers were required to register behaviors of each calf by direct observation by scanning for all predefined behaviors. Reliability $>95 \%$ was determined and checked weekly. Scan sampling pen means were calculated, and a treatment mean determined each week for $7 \mathrm{wk}$.

The second method was continuous focal sampling of each calf in group pens. Each group pen was fitted with a digital camera (15 cameras/15 group pens/replicate) positioned approximately $3 \mathrm{~m}$ above the ground, which ensured a full view of the entire pen and the feeding buckets and bottles. Behavior was recorded by video cameras (CBHD39N-L; Nuvico Corp., Englewood, NJ) between 1400 and $1600 \mathrm{~h}$, with feeding beginning at $1430 \mathrm{~h}$. Output from the cameras was recorded with Easy Net (DVRED-U1600; Nuvico Corp.) digital video recorder. Continuous observations were conducted by a single observer using Observer XT (version 5; Noldus Information Technology, Wageningen, the Netherlands). Each calf in the group was observed continuously for 5 min for duration and frequency of milk feeding, displacement, cross-sucking, and play behaviors (social, locomotor, and object). The start and stop of each respective 5 -min observation window was defined by delivery of milk bottles and the end of milk feeding for the individual calf (calf lying down or returning to their hutch), respectively.

Calves were weighed individually upon arrival to determine initial BW and at the end of the experiment (final BW). Body weight gain was final minus initial BW. The means $( \pm \mathrm{SE})$ of total plasma protein concentrations were $5.17 \pm 0.2,5.18 \pm 0.2$, and $5.25 \pm$ 
Table 1. Ethogram of recorded of behavioral patterns and their description in group-housed dairy calves

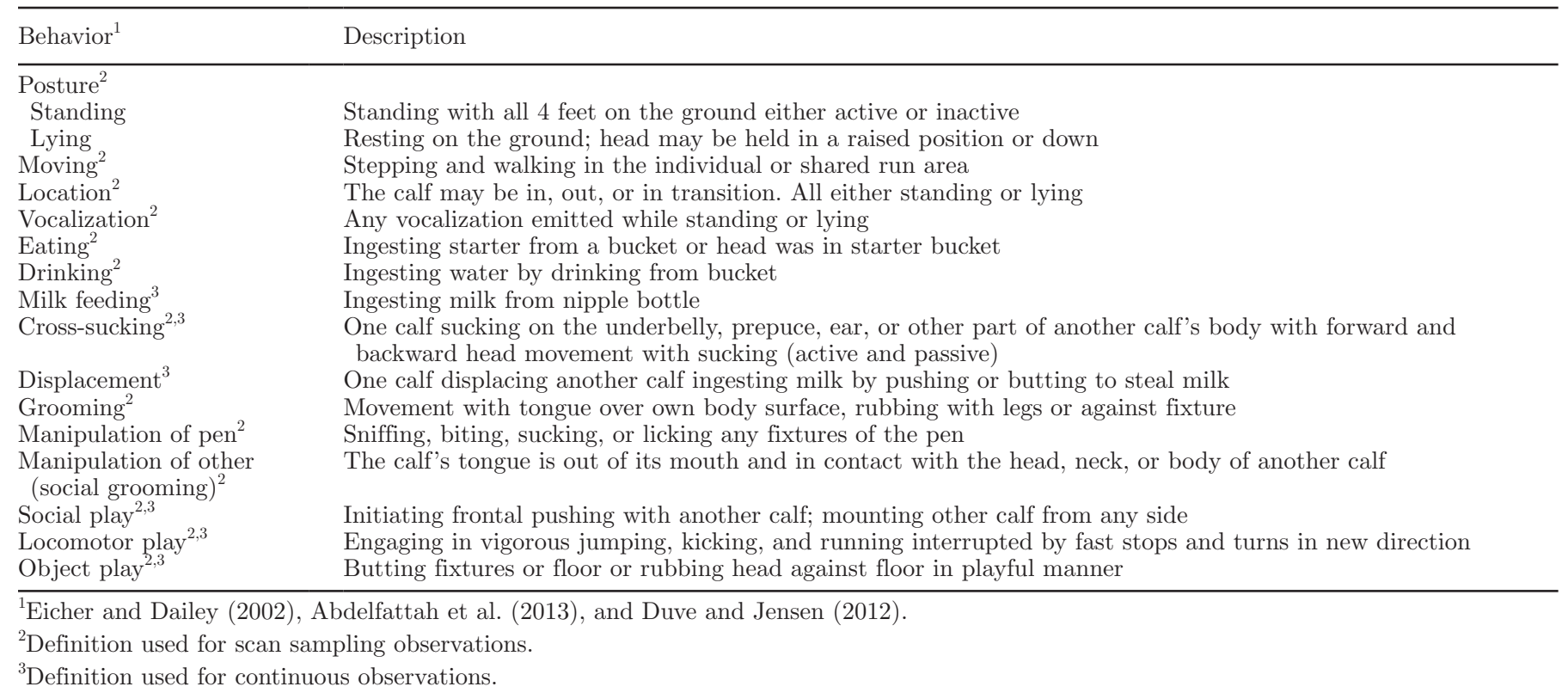

$0.3 \mathrm{~g} / \mathrm{dL}$ for calves assigned in GH3, GH7, and GH14 respectively. Hip height and heart girth were measured at enrollment for all calves and then weekly for one focal calf from each pen until the end of the experiment. Besides the daily check of calf health by the farm crew, health checks were performed upon arrival of calves and then weekly on all calves until the end of the experiment by trained, experienced personnel. Health was scored using the University of Wisconsin calf health scoring chart (McGuirk, 2008). Two calves in each of GH3 and GH7 and 1 in GH14 had fecal scores of 4 and were treated with electrolyte solutions (Bluelite C, TechMix LLC, Stewart, MN). The observers monitored each calf daily at the time of milk feeding for the first week of grouping. If a calf was unable to find the teat or was disturbed by other calves, the observer guided those calves to their bottles. The percentage of calves that needed help to find the bottle during the first week of grouping was calculated for each treatment.

Blood samples were collected from one calf from each pen $(\mathrm{n}=30)$ within $1 \mathrm{~h}$ of grouping for determination of plasma cortisol concentration and preparation of slides for differential leukocyte counts, and then blood was collected at d 3, 7, and 14 relative to the day of grouping for differential leukocyte counts. Blood was collected into two $10-\mathrm{mL} \mathrm{K}_{3}$-EDTA vacuum tubes (Monoject, Mansfield, MA) for separation of plasma for cortisol concentration and preparation of slides for differential leukocyte counts. Plasma was collected after centrifugation at $1,500 \times g$ for $15 \mathrm{~min}$ and stored at $-80^{\circ} \mathrm{C}$ until subsequent analyses. Plasma cortisol concentrations were measured by RIA (Coat-a-Count RIA
Cortisol kit, Siemens Healthcare Diagnostics Inc., Los Angeles, CA). The protocol has been previously validated in our laboratory for measuring bovine plasma cortisol concentrations (Eicher et al., 2007). Inter- and intraassay coefficients of variation were $4.0 \%$ and $4.4 \%$, respectively.

A randomized complete block design with repeated measures using PROC MIXED was applied to each variable using SAS 9.4 (SAS Institute Inc., Cary, NC) with the covariance between repeated measures of pen modeled using compound symmetry. Pens of 3 calves or a group of 3 individual pens was the experimental unit and used as a random effect. The data were tested for normality using the PROC UNIVARIATE procedure in SAS and normal plot of residuals. Reported differences are based on normalized data.

For instantaneous scan sampling, the percentage of behavioral observations was calculated by dividing the total number of observation records of a behavior within $3 \mathrm{~h}$ by instantaneous scan sampling points (18 points total) and analyzed using a model that included age at grouping (treatment, GH3, GH7, GH14), week (from wk 1 to wk 7), and treatment $\times$ week interactions as fixed effects. The variables "transition to pen," "vocalization," "play," and "cross-sucking" were not normally distributed and transformed using square root transformation before analysis.

For data recorded continuously, only data of the first replicate are reported due to technical error. Before analysis, the mean for each pen was calculated for all measured variables (milk feeding, displacement, play, and cross-sucking behaviors). The variables "cross- 
sucking" and "displacement" were transformed by square root transformation before analysis. The model included treatment, week after grouping (wk 4, 5, 6, and 7 ), and treatment $\times$ week interactions as fixed effects.

Initial and final BW, BW gain, and ADG means were calculated per pen before analysis. The model included treatment as fixed effect. For growth measures (hip height and heart girth) and health scores (fecal, cough, nasal and ocular discharge scores), the model included treatment and week (from wk 1 to 7 ) as fixed effects and their interactions.

The differential leukocyte count model included treatment, day of sample collection (1 h, d 3, 7, and 14 after grouping), and treatment $\times$ day interactions as fixed effects, and calf identity was entered as a random effect. The model used for cortisol concentration included only treatment as the fixed effect at $1 \mathrm{~h}$ after grouping. Least squares means and SEM were reported for each variable and level of statistical significance was reported at a $P$-value of $\leq 0.05$.

An interaction of treatment and week was observed for vocalization $\left(F_{12,170}=2.75, P<0.01\right.$; Figure $\left.1 \mathrm{~A}\right)$. During wk 2 to 5 of the experiment, GH14 calves vocalized more than GH3 and GH7 calves. It is interesting to note that calves in GH3 had a peak of vocalizations that quickly returned to baseline, those in GH7 showed no peak, but the greater vocalizations of those in GH14 persisted for several weeks. This could be because calves become less socially flexible even over that short period. Bolt et al. (2017) showed that postweaning vocalizations were greater for individually housed calves but did not differ between those grouped at 5 and 28 $\mathrm{d}$, showing that early housing affects vocalization at later stressful times. We did not measure vocalizations postweaning but, in contrast to the postweaning data
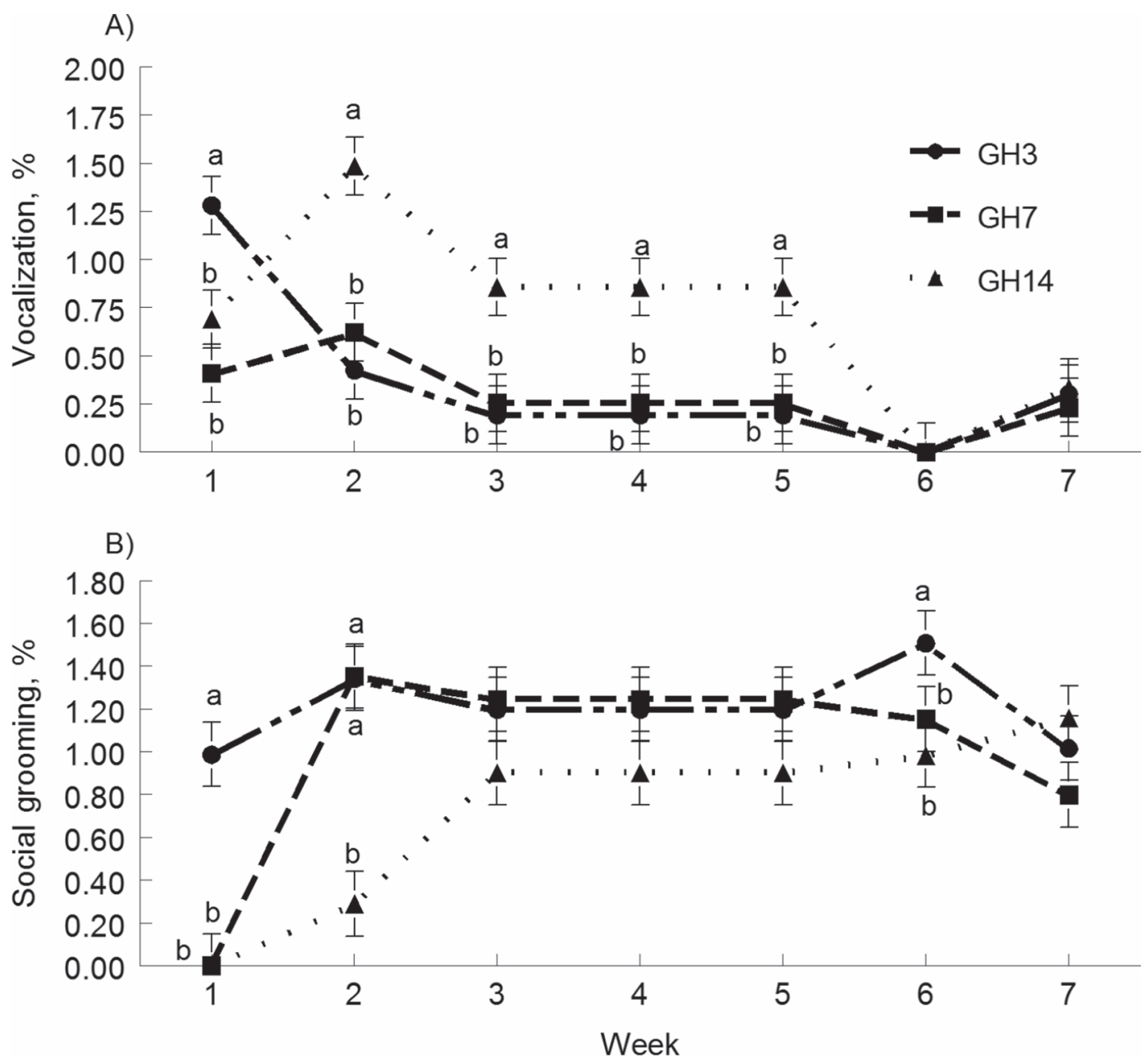

Figure 1. The effect of calf's age on the percentage of calves observed in (A) vocalizations (age at grouping $\times$ week, $P=0.02)$ and $(B)$ social grooming (age at grouping $\times$ week, $P=0.03$, panel $\mathrm{B}$ ) during instantaneous scan sampling during wk 1 to 7 of the experiment. Age at grouping treatments: GH3, GH7, and GH14 = calves that were group-housed at $3 \pm 1 \mathrm{~d}, 7 \pm 1 \mathrm{~d}$, and $14 \pm 1 \mathrm{~d}$ of age, respectively. Results are presented as the least squares means $( \pm \mathrm{SEM})$ of untransformed data. Means within a day with different letters $(\mathrm{a}, \mathrm{b})$ differ $(P \leq 0.05)$. 
of Bolt et al. (2017), our work suggests that grouping at $\mathrm{d} 3$ or 7 appeared to reduce vocalization, indicating less stress even before weaning.

Scan sampling for social interactions (social grooming) showed an interaction between treatment and week $\left(F_{12},{ }_{188}=3.04, P=0.001 ;\right.$ Figure $\left.1 \mathrm{~B}\right)$. Social interaction was greater in GH3 calves than GH7 and GH14 calves at wk 6 when gradual weaning was initiated. However, during wk 3, 4, 5, and 7, social interaction was not different among grouping treatments. Early (wk 1 to 3 ) social interaction changes reflect the time of grouping. Social interactions occur only $2 \%$ of the time in the first $8 \mathrm{wk}$ (Chua et al., 2002). Duve and Jensen (2012) reported minor differences in social sniffing and licking between calves housed together from birth compared with those paired at 3 wk of life. However, Rasmussen et al. (2006) failed to find any significant effect of age at introduction (6 vs. 14 d) on any measures of social behavior (licking, sniffing, and manipulating of another calf) among calves fed from a computer-controlled milk feeder. Through cognitive tests, Meagher et al. (2015) found a cognitive advantage of early grouping. Our results confirm that individual housing limits calves in expression of social behaviors, but they all exhibit social behaviors when given the opportunity, regardless of age. Because effects of early social interaction persist into adulthood (Costa et al., 2016), there may be a sensitive period for social bond formation in calves.
During instantaneous scan sampling (Table 2), more calves were observed playing in GH3 than GH7 and GH14 $\left(F_{2,189}=6.39, P=0.03\right)$. The percentage of calves performing play behavior peaked at wk 3 and declined by wk $6(P<0.001)$, supporting earlier work of Jensen et al. (1998), Jensen and Kyhn (2000), and Duve and Jensen (2012). Milk was adequate to support some play, but increasing milk allowance has been found to increase the occurrence of play (Jensen et al., 2015). The low duration of play behavior in the current study could be attributed to calves being fed $6 \mathrm{~L} / \mathrm{d}$ and consuming more dry feed (Jensen et al., 2015). Other behavioral measures assessed by scan sampling were not affected $(P>0.05)$ by treatment groups throughout the experiment.

Continuous behavioral observations around feeding time revealed that treatment affected duration of displacement at milk feeding and cross-sucking. In this study, calves were only observed by continuous observations for 5 min because, within that time, milk was consumed and calves had either retreated to the hutches or had lain down. The duration of displacement from bottles was greater for GH3 and GH7 calves than GH14 calves $\left(F_{2,12}=15.02, P<0.01\right.$; Table 3$)$.

Duration of cross-sucking was greater $\left(F_{2,12}=3.29\right.$, $P<0.01$; Table 3) among GH3 and GH7 calves than in GH14 calves, which may merely reflect the longer duration of group housing. Motivation and ways to minimize

Table 2. Mean percentage of observations ${ }^{1}\left(\mathrm{LSM} \pm \mathrm{SE}^{2}\right)$ of neonatal dairy calves (15 pens per treatment) that were group-housed at $3 \pm 0.8 \mathrm{~d}$ (GH3), $7 \pm 0.8 \mathrm{~d}$ (GH7), and $14 \pm 0.8 \mathrm{~d}$ (GH14) of age using 10-min instantaneous scan sampling

\begin{tabular}{|c|c|c|c|c|c|c|}
\hline \multirow[b]{2}{*}{ Behavior, $\%$ of observations } & \multicolumn{3}{|c|}{ Treatment $(\mathrm{Trt})^{3}$} & \multicolumn{3}{|c|}{$P$-value ${ }^{4}(\leq)$} \\
\hline & GH3 & GH7 & GH14 & Trt & $\mathrm{Wk}$ & Trt $\times W k$ \\
\hline Standing & $30.3 \pm 3.12$ & $27.7 \pm 3.33$ & $28.8 \pm 3.33$ & 0.84 & 0.01 & 0.93 \\
\hline Lying & $69.2 \pm 2.92$ & $70.5 \pm 3.12$ & $70.3 \pm 3.12$ & 0.95 & 0.01 & 0.99 \\
\hline Location (inside the hutch) & $66.1 \pm 2.86$ & $65.7 \pm 3.05$ & $70.2 \pm 3.08$ & 0.53 & 0.01 & 0.97 \\
\hline Location (outside the hutch) & $32.3 \pm 2.90$ & $31.4 \pm 3.10$ & $27.3 \pm 3.10$ & 0.47 & 0.01 & 0.97 \\
\hline Location (transition to hutch) & $1.05 \pm 0.23$ & $0.7 \pm 0.24$ & $0.6 \pm 0.24$ & 0.91 & 0.01 & 0.98 \\
\hline Eating solid feed & $1.4 \pm 0.31$ & $1.2 \pm 0.33$ & $2.0 \pm 0.33$ & 0.28 & 0.01 & 0.87 \\
\hline Drinking (milk and water) & $1.4 \pm 0.25$ & $0.9 \pm 0.27$ & $0.7 \pm 0.27$ & 0.15 & 0.01 & 0.38 \\
\hline Elimination & $0.4 \pm 0.21$ & $0.5 \pm 0.22$ & $0.3 \pm 0.22$ & 0.71 & 0.04 & 0.98 \\
\hline Movement & $1.5 \pm 0.47$ & $1.2 \pm 0.50$ & $1.7 \pm 0.50$ & 0.79 & 0.21 & 0.11 \\
\hline Grooming & $3.0 \pm 0.42$ & $3.6 \pm 0.45$ & $2.9 \pm 0.45$ & 0.45 & 0.01 & 0.86 \\
\hline Manipulation of pen & $7.7 \pm 1.40$ & $9.2 \pm 1.50$ & $9.2 \pm 1.50$ & 0.69 & 0.01 & 0.12 \\
\hline Licking other calf (social grooming) $)^{5}$ & $2.4 \pm 0.53$ & $2.7 \pm 0.57$ & $1.6 \pm 0.57$ & 0.33 & 0.01 & 0.01 \\
\hline Rumination & $8.9 \pm 1.28$ & $7.8 \pm 1.36$ & $8.3 \pm 1.36$ & 0.84 & 0.01 & 0.83 \\
\hline Vocalization & $0.6 \pm 0.37^{\mathrm{b}}$ & $0.7 \pm 0.39^{\mathrm{b}}$ & $1.9 \pm 0.39^{\mathrm{a}}$ & 0.16 & 0.01 & 0.01 \\
\hline Play (locomotive, social, and objects) & $1.6 \pm 0.48^{\mathrm{a}}$ & $0.4 \pm 0.51^{\mathrm{b}}$ & $0.1 \pm 0.51^{\mathrm{b}}$ & 0.03 & 0.01 & 0.78 \\
\hline Cross-sucking 5 & $1.9 \pm 1.12$ & $1.6 \pm 1.20$ & $0.1 \pm 1.20$ & 0.20 & 0.01 & 0.93 \\
\hline
\end{tabular}

\footnotetext{
${ }^{\mathrm{a}, \mathrm{b}}$ Means in a row followed by same superscript letter are not significantly different $(P>0.05)$.

${ }^{1}$ Number of observations per $3 \mathrm{~h}$ of 10 -min instantaneous scan sampling. Total observations $=18$.

${ }^{2}$ Least squares means of untransformed data.

${ }^{3} \mathrm{n}=10$ pens/treatment with 3 calves/pen.

${ }^{4}$ Reported differences are based on normalized data after log-transformation.

${ }^{5}$ Data for this variable did not include wk 0 to 2 , because there was no opportunity for it to occur in the late grouped calves.
} 
cross-sucking have been reported by de Passillé (2001), Jensen (2003), Jensen and Weary (2013), and Hulbert et al. (2015). Prolonging the milk meal by decreasing flow and ensuring access to an artificial teat after the meal are methods to decrease cross-sucking. Calves that have greater solid feed consumption and access to higher quality feed performed less cross-suckling (Keil and Langhans, 2001). Calves at $14 \mathrm{~d}$ are more likely to have started eating dry feed and thus may be less likely to develop cross-sucking.

Age at grouping did not affect final BW, BW gain, or ADG $\left(F_{2,26}=3.99, P>0.05\right)$. Average daily gain (mean $\pm \mathrm{SE}$ ) was similar among treatment groups $(0.8$ $\pm 0.04,0.7 \pm 0.04$, and $0.7 \pm 0.04 \mathrm{~kg} / \mathrm{d}$ for GH3, GH7, and GH14, respectively, $F_{2,27}=1.02, P=0.49$ ). In divergence with our expectations, we found that treatment had no effect on calf performance or health. Costa et al. (2016) showed that grouping studies had either equal or improved performance responses with group housing. In contrast to our data, De Paula Vieira et al. (2010) reported that pair housing improved performance. Our results support the idea that grouping calves soon after birth had no adverse effect on growth performance or health. However, in our study, calves grouped at d 3 required more $(P=0.05)$ guidance to milk bottles than calves grouped at d 7 or 14 (Table 4) to avoid milk stealing.

Hip height and heart girth increased $\left(F_{5,160}=23.23\right.$, $P<0.001)$ as calf age advanced; however, neither hip height $\left(F_{2,160}=3.04, P=0.87\right)$ nor heart girth $\left(F_{2,160}\right.$ $=3.11, P=0.32)$ was affected by treatment. Also, no effect $\left(F_{2,162}=0.66, P>0.05\right)$ of treatment was found on health status scores (Table 4), including fecal, cough, ocular discharge, or nasal discharge scores. This was similar to Bolt et al. (2017), who found no differences in fecal scores or respiratory scores for individually housed or calves grouped at 5 or $28 \mathrm{~d}$ of age, and Jensen and Larsen (2014), who reported no effect of group housing on health scores.

Treatments were not different for leukocyte count $\left(F_{2,12.6}=0.26, P \geq 0.05\right.$; data not shown $)$, a sensitive measure of stress among cattle (Hulbert and Ballou, 2012). However, a day effect was reported for the percentage of neutrophils, lymphocytes, and monocytes $\left(F_{6,67.2}=0.88, P<0.001\right)$, with increasing lymphocytes and decreasing neutrophils, as is typical for growing calves with means within the normal ranges (Mohri et al., 2007). Lymphocyte percentages (mean \pm SE) for wk 1 to 7 were $30,29,28,35,61,72$, and $43 \pm 3$. Vaccinations were given at wk 4 . A corresponding increase in percentage of lymphocytes was observed in all calves at wk 5 and 6 .

We detected no treatment effect on plasma cortisol concentrations on the day of grouping for each treat-

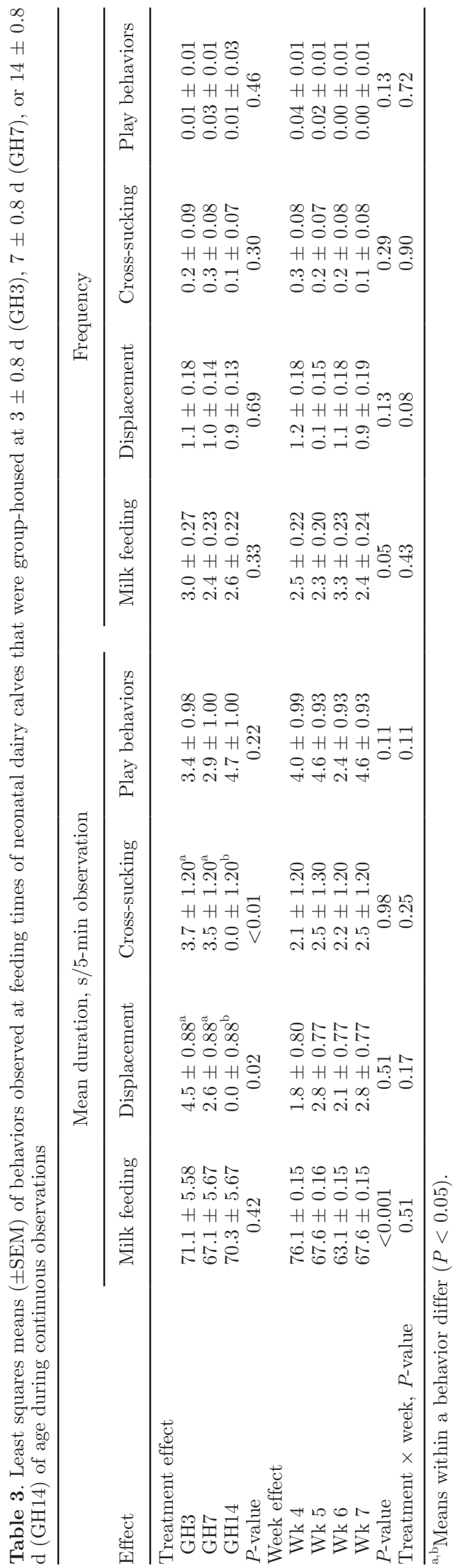

Journal of Dairy Science Vol. 101 No. 1, 2018 
Table 4. Health scores of neonatal dairy calves that were group-housed at $3 \pm 1 \mathrm{~d}$ (GH3), $7 \pm 1 \mathrm{~d}$ (GH7), and 14 $\pm 1 \mathrm{~d}$ (GH14) of age

\begin{tabular}{|c|c|c|c|c|c|c|}
\hline Variable & \multicolumn{3}{|c|}{ Treatment (Trt) } & \multicolumn{3}{|c|}{$P$-value } \\
\hline Fecal score ${ }^{1}$ & $1.9 \pm 0.07$ & $1.8 \pm 0.07$ & $1.7 \pm 0.07$ & 0.33 & $<0.001$ & 0.21 \\
\hline Cough $^{1}$ & $1.2 \pm 0.07$ & $1.3 \pm 0.07$ & $1.2 \pm 0.07$ & 0.36 & $<0.001$ & 0.98 \\
\hline Nasal discharge $^{1}$ & $1.5 \pm 0.08$ & $1.5 \pm 0.08$ & $1.7 \pm 0.08$ & 0.35 & $<0.001$ & 0.57 \\
\hline Guidance to milk bottle ${ }^{2}$ & $24.7 \pm 4.01^{\mathrm{a}}$ & $12.4 \pm 4.01^{\mathrm{b}}$ & $11.4 \pm 4.01^{\mathrm{b}}$ & 0.05 & - & - \\
\hline
\end{tabular}

${ }_{\mathrm{a}, \mathrm{b}}$ Means $( \pm \mathrm{SEM})$ within a row with differing superscripts differ $(P \leq 0.05)$.

${ }^{1}$ Fecal, ocular discharge, cough, and nasal discharge scores based on McGuirk (2008).

${ }^{2}$ Percentage of calves guided to milk bottle within the first week of group housing $(\mathrm{n}=15$ per treatment).

ment $(P=0.17)$. Plasma cortisol concentrations within $1 \mathrm{~h}$ of grouping were $26.1 \pm 8.2,28.4 \pm 7.1$, and $25.9 \pm$ $7.1 \mu \mathrm{g} / \mathrm{dL}$ for GH3, GH7, and GH14 respectively.

In conclusion, calves that were group-housed just after $3 \mathrm{~d}$ of age had more social interactions, performed more play behavior, and vocalized less than calves that were group-housed when 7 or $14 \mathrm{~d}$ old. These data show no adverse effects on health or performance and some benefits on social behavior for early (d 3) grouping of calves.

\section{REFERENCES}

Abdelfattah, E. M., M. M. Schutz, D. C. Lay Jr., J. N. Marchant-Forde, and S. D. Eicher. 2013. Effect of group size on behavior, health, production, and welfare of veal calves. J. Anim. Sci. 91:5455-5465.

Bolt, S. L., H. K. Boyland, D. T. Mlynski, R. James, and D. P. Croft. 2017. Pair housing of dairy calves and age at pairing: effects on weaning stress, health, production, and social networks. PLoS One 12:e0166926.

Chua, B., E. Coenen, J. Van Delen, and D. M. Weary. 2002. Effects of pair versus individual housing on the behavior and performance of dairy calves. J. Dairy Sci. 85:360-364.

Cobb, C. J., B. S. Obeidat, M. D. Sellers, A. R. Pepper-Yowell, and M. A. Ballou. 2014. Group housing of Holstein calves in a poor indoor environment increases respiratory disease but does not influence performance or leukocyte responses. J. Dairy Sci. 97:3099-3109.

Costa, J. H., M. A. G. von Keyserlingk, and D. M. Weary. 2016. Invited review: Effects of group housing of dairy calves on behavior, cognition, performance, and health. J. Dairy Sci. 99:2453-2467.

Costa, J. H. C., R. K. Meagher, M. A. G. von Keyserlingk, and D. M. Weary. 2015. Early pair housing increases solid feed intake and weight gains in dairy calves. J. Dairy Sci. 98:6381-6386.

de Passillé, A. M. 2001. Sucking motivation and related problems in calves. Appl. Anim. Behav. Sci. 72:175-187.

De Paula Vieira, A., M. A. G. von Keyserlingk, and D. M. Weary. 2010. Effects of pair versus single housing on performance and behavior of dairy calves before and after weaning from milk. J. Dairy Sci. 93:3079-3085.

Duve, L. R., and M. B. Jensen. 2012. Social behavior of young dairy calves housed with limited or full social contact with a peer. J. Dairy Sci. 95:5936-5945.

Eicher, S. D., and J. W. Dailey. 2002. Indicators of acute pain and fly avoidance behaviors in Holstein calves following tail-docking. J. Dairy Sci. 85:2850-2858.

Eicher, S. D., M. Schutz, F. Kearney, S. Willard, S. Bowers, S. Gandy, and K. Graves. 2007. Prepartum milking effects on parlour behaviour, endocrine and immune responses in Holstein heifers. J. Dairy Res. 74:417-424.
Hulbert, L. E., and M. A. Ballou. 2012. Innate immune responses and health of individually reared Holstein calves after placement into transition-pens 23 d after weaning. J. Dairy Res. 79:333-340.

Hulbert, L. E., and S. J. Moisá. 2016. Stress, immunity, and the management of calves. J. Dairy Sci. 99:3199-3216.

Hulbert, L. H., S. C. Trombetta, P. Kate, K. P. Sharon, and M. A. Ballou. 2015. Milk replacer plane of nutrition influences calf nutritive and non-nutritive oral behaviors. J. Dairy Sci. 98(Suppl. 2):562. (Abstr.)

Jensen, M. B. 2003. The effects of feeding method, milk allowance and social factors on milk feeding behavior and cross-sucking in group housed dairy calves. Appl. Anim. Behav. Sci. 80:191-206.

Jensen, M. B. 2007. Age at introduction to the group affects dairy calves' use of a computer-controlled milk feeder. Appl. Anim. Behav. Sci. 107:22-31.

Jensen, M. B., L. R. Duve, and D. M. Weary. 2015. Pair housing and enhanced milk allowance increase behavior and improve performance in dairy calves. J. Dairy Sci. 98:2568-2575.

Jensen, M. B., and R. Kyhn. 2000. Play behavior in group-housed dairy calves, the effect of space allowance. Appl. Anim. Behav. Sci. $67: 35-46$.

Jensen, M. B., and L. E. Larsen. 2014. Effects of level of social contact on dairy calf behavior and health. J. Dairy Sci. 97:5035-5044.

Jensen, M. B., K. S. Vestergaard, and C. C. Krohn. 1998. Play behavior in dairy calves kept in pens: the effect of social contact and space allowance. Appl. Anim. Behav. Sci. 56:97-108.

Jensen, M. B., and D. M. Weary. 2013. Group housing and milk feeding of dairy calves. Adv. Dairy Technol. 25:179-189.

Keil, N. M., and W. Langhans. 2001. The development of intersucking in dairy calves around weaning. Appl. Anim. Behav. Sci. 72:295308.

Martin, P., and P. Bateson. 2007. Recording methods. Pages 48-60 in Measuring Behaviour: An Introductory Guide. 3rd ed. Cambridge Univ. Press, Cambridge, UK.

McGuirk, S. M. 2008. Disease management of dairy calves and heifers. Vet. Clin. North Am. Food Anim. Pract. 24:139-153.

Meagher, R. K., R. R. Daros, J. H. C. Costa, M. A. G. von Keyserlingk, M. J. Hötzel, and D. M. Weary. 2015. Effects of degree and timing of social housing on reversal learning and response to novel objects in dairy calves. PLoS One 10:e0132828.

Mhori, M., K. Sharifi, and S. Eidi. 2007. Hematology and serum biochemistry of Holstein dairy calves: Age related changes and comparison with blood composition in adults. Res. Vet. Sci. 83:30-39.

Rasmussen, L., M. B. Jensen, and L. L. Jeppesen. 2006. The effect of age at introduction and number of milk-portions on the behaviour of group housed dairy calves fed by a computer controlled milk feeder. Appl. Anim. Behav. Sci. 100:153-163.

USDA. 2011. Dairy Heifer Raiser. 2011. USDA, National Animal Health Monitoring System, Fort Collins, CO.

Valníčková, B., I. Stehulova, R. Sarova, and M. Spinka. 2015. The effect of age at separation from the dam and presence of social companions on play behavior and weight gain in dairy calves. J. Dairy Sci. 98:5545-5556. 